\title{
The Effect of Primary Particle Polydispersity on the Morphology and Mobility Diameter of the Fractal Agglomerates in Different Flow Regimes
}

\author{
Ramin Dastanpour ${ }^{1, \mathrm{a}}$ and Steven N. Rogak ${ }^{1}$, \\ ${ }^{1}$ Department of Mechanical Engineering, University of British Columbia \\ 6250 Applied Sciences Lane, Vancouver, BC, Canada, V6T 1Z4 \\ ${ }^{a}$ Corresponding author: e-mail: r.dastanpour@alumni.ubc.ca; Fax: +1-604-822-2403
}




\begin{abstract}
Properties of colloidal and aerosol agglomerates depend on their morphology. Accurate estimation of the mobility-equivalent diameter $d_{\mathrm{m}}$ in different flow regimes is essential in many industrial processes and measurements. Previous work on the hydrodynamic properties of clusters focussed on agglomerates composed of monodisperse primary particles. However aggregates formed in real processes, e.g. soot particles, are usually formed from polydisperse monomers. Using numericallygenerated agglomerates it is shown here that the radius of gyration, surface area, and mass of the agglomerates increase with primary particle polydispersity (given constant geometric mean primary particle size $d_{\mathrm{pg}}$ ). Here, $d_{\mathrm{m}}$ is taken as the projected area-equivalent diameter for the free molecular regime; Stokesian Dynamics is used to compute $d_{\mathrm{m}}$ in the continuum flow regime. For fixed number of primaries and $d_{\mathrm{pg}}, d_{\mathrm{m}}$ increases with polydispersity in both free molecular and continuum regimes (>20\% for large particles at high polydispersity). Considering an aerosol population with polydisperse primary particles, this increase is found to depend on whether the variations in primary particle size occur within aggregates or between aggregates; this can be important in the interpretation of measurements. Finally, mobility diameters are correlated with total number, median diameter and its geometric standard deviation of the primary particles.
\end{abstract}

\title{
Keywords:
}

Mobility diameter; Primary particle polydispersity; Free molecular regime; Continuum regime; Stokesian Dynamics; Radius of gyration

\section{Introduction}

Aerosol and colloidal agglomerates of smaller primary particles are formed in many industrial and natural environments. While some nanoparticle aggregates are potentially useful, soot aggregates formed by incomplete combustion of hydrocarbons are known responsible for adverse health effects Peretz et al., (2008) and climate forcing Hansen \& Nazarenko (2004).

Production rate and properties of synthetic particles, aerosol residence time in atmosphere, and its dispersion rate and motion under different flow regimes are influenced by the morphology and hydrodynamic properties of these particles. Reliable measurement of the emission rate and size distribution of fractal aggregates also depend on accurate estimation of the morphology and mobility of these particles.

Great effort has been devoted to the estimation of the hydrodynamic properties of straight chains and fractal agglomerates in different flow regimes. The mobility of the aerosols of different structures is usually expressed by an equivalent mobility diameter $\left(d_{\mathrm{m}}\right)$. This diameter is equal to the diameter of a virtual sphere experiencing the same drag force under the same flow condition. Experimental measurements have been performed to correlate the mobility diameter of the fractal aggregates to the structure, e.g. radius of gyration $\left(R_{\mathrm{g}}\right)$, primary particle diameter $\left(d_{\mathrm{p}}\right)$, and projected area of these particles (Binder et al., 2009; Gmachowski, 2007; Gwaze et al., 2006; Johnson et al., 1996; Rogak at al., 1993; Thajudeen et al., 2015; Wang \& Sorensen, 1999).

Several simulations have also been carried out to calculate the mobility diameter of clusters in different flow regimes. In the free molecular regime, the mobility diameter of the fractal 
aggregates, $d_{\mathrm{m}, \mathrm{fm}}$, is approximately equal to their average projected area equivalent diameter, $d_{\mathrm{a}}$, (Rogak et al., 1993). This is consistent with the results obtained from Monte Carlo simulations of momentum transfer rate of chains and fractal aggregates in this regime (Chan \& Dahneke, 1981; Mackowski, 2006; Thajudeen et al., 2012). Consequently, if primary particle size variation is to influence particle mobility in this regime, it should be limited to the geometric relation between the number of primary particles and the projected area.

Calculation of the effect of morphology on continuum regime mobility is not as simple as the free molecule regime. Several methods have been developed for the assessment of the mobility diameter of aggregates in this regime. A group of these methods treats aggregates as porous spheres of homogeneous (Rosner \& Tandon, 1994) or variable permeability (Kim \& Yuan, 2005). The Lattice Boltzmann Method (LBM) has been used for the investigation of hydrodynamic properties of fractal aggregates by many researchers (Binder et al., 2006; Schlauch et al., 2013; Ulrich et al., 2008). Brownian dynamics approach has also been used in several studies (Douglas et al., 1994; Gopalakrishnan, et al., 2011; Thajudeen et al., 2012; Zhang et al.,2012) for the estimation of the collision kernels of particles and surrounding gas molecules, and mobility diameters of particles of irregular shapes in the continuum regime. As an another approach the Finite Element Method (FEM) has also been used for the investigation of the hydrodynamic properties of clusters in this regime (Melas et al., 2014; Schlauch et al., 2013). Although these methods provide high accuracy, they are usually computationally expensive. Kirkwood-Riseman theory of hydrodynamic interaction of particles is another method commonly used for the calculation of the drag force on clusters of spherical particles (Chen et al., 1987; Kirkwood \& Riseman, 1948; Lattuada et al., 2003; Meakin et al., 1985).

One of the most accurate methods commonly used for the simulation of the hydrodynamic interactions between aggregates and flow field in the limiting case of low Reynolds number, creeping flow, is referred to as Stokesian Dynamics (SD) (Binder et al., 2006; Bossis et al., 1991; Filippov, 2000; Harada et al., 2006; Harshe et al., 2010; Schlauch et al., 2013; Seto et al., 2011). In this method the flow disturbance caused by the non-overlapping monomers in clusters is modeled through the superposition of point forces on the surface of the monomers. The multipole expansion of the flow velocity in a series of spherical harmonics is used and the hydrodynamic interactions are simulated by a combination of far-field mobility and pairwise additive resistance calculations. Hydrodynamic interactions of two equal (Jeffrey \& Onishi, 1984) and unequal (Ichiki at al., 2013; Jeffrey \& Onishi, 1984) spheres in different flow patterns are modeled by the Stokesian Dynamics method through the construction of resistance and mobility matrices which purely depend on the diameter and relative arrangement of primary particles in regards to the flow field. Application of SD to N-body clusters was pioneered by Brady \& Bossis (1988) and Durlofsky et al., (1986). As confirmed by rigorous numerical simulations of Gwaze et al. (2006) and Schlauch et al. (2013), SD provides good accuracy with modest computational time.

In large clusters, it is commonly assumed that the hydrodynamic radius becomes proportional to the radius of gyration (Sorensen, 2011):

$$
R_{\mathrm{m}, \mathrm{c}}=\beta R_{\mathrm{g}}
$$

This proportionality was first investigated by Chen et al. (1987) and Meakin et al. (1985). Using Kirkwood-Riseman theory, they obtained $\beta=0.875$ for particles generated by Diffusion Limited Cluster-cluster Aggregation (DLCA) composed of 50 to 400 monodisperse primary particles. 
Studies performed by Rogak \& Flagan (1990), Wang \& Sorensen (1999), Wiltzius (1987), and Sorensen (2011) suggested $\beta$ to be in the range of 0.68 to 0.78 for DLCA aggregates with a fractal dimension $\left(D_{\mathrm{f}}\right)$ of 1.78 . However, as it will be discussed later in this article, a wide range of values are reported in literature for $\beta$.

Although an extensive body of literature is already available for the simulation of the hydrodynamic properties of the fractal aggregates in different flow regimes, previous studies are limited to the clusters composed of monodisperse monomers. However, particles formed in different environments are shown to be composed of monomers of different levels of polydispersity (Dastanpour \& Rogak, 2014; Heine \& Pratsinis, 2007). Eggersdorfer \& Pratsinis (2012) have showen that the fractal dimension of aggregates decreases with primary particle polydispersity. The influence of the primary particle polydispersity on the morphology (i.e. surface area, mass, and radius of gyration), and hydrodynamic behaviour of particles in the free molecular and continuum regimes are investigated in the current study.

\section{Methods}

Algorithms used for the generation of numerical aggregates and calculation of the mobility diameters of these particles in free molecular and continuum flow regimes are described in the following sections. The transition regime case is not discussed here because an established interpolation approach (Zhang et al., 2012) can be used for the calculation of the mobility diameter at arbitrary Knudsen number, given the two limiting cases of free molecular and continuum regimes. Application of the interpolation to averages for the limiting regime cases is not identical to interpolating first, then averaging over individual aggregates, but this effect is not considered in this paper.

\subsection{Generation of the Numerical Agglomerates}

Mobility calculations were performed on numerical particles including straight chains and threedimensional fractal agglomerates of point-touching spheres. Straight chains were composed of 1 to 1000 monodisperse primary particles and were only used for validation purposes.

Fractal agglomerates were generated by Eggersdorfer \& Pratsinis (2013) using a hierarchical cluster-cluster agglomeration algorithm (Botet et al., 1984; Eggersdorfer \& Pratsinis, 2013). Aggregates were composed of 16, 32, 64, 128, 256, and 512 point-touching primary particles. The primary particle size distribution of aggregates generated by different sources can usually be well represented by a lognormal size distribution (Boies et al., 2015; Dankers \& Leipertz, 2004; Dastanpour \& Rogak, 2014; Graves et al., 2015; Johnson et al., 2015; Liu et al., 2006; Wu et al., 2015). Detailed comparison of normal and lognormal fits to primary particle size distributions obtained from the analysis of real soot images produced by transmission electron microscopy (section 1, online supplementary information) confirms the suitability of the lognormal assumption. Considering the experimental results obtained from the analysis of a large group of the TEM images reported in our previous work (Dastanpour \& Rogak, 2014), primary particle diameters were selected randomly from lognormal distributions with geometric standard deviations $\left(\sigma_{\mathrm{g}}\right)$ of 1.0,1.2, 1.4, and 1.6. The polydispersity of the primary particles was also checked for the generated particles to compensate the stochastic errors rising from the limited number of the primary particles in small aggregates. One hundred aggregates were generated for each $\sigma_{\mathrm{g}}$ and number of primary particles $\left(N_{\mathrm{p}}\right)$ for a total of 2400 aggregates. 


\subsection{Free Molecular Regime}

In the free molecular regime, the average mobility diameter of an arbitrary shaped particle is approximately equal to its average projected area equivalent diameter, $\overline{d_{\mathrm{a}}}$ :

$$
d_{\mathrm{m}, \mathrm{fm}} \cong \overline{d_{\mathrm{a}}}=2 \sqrt{\frac{\overline{a_{\mathrm{a}}}}{\pi}}
$$

where $\overline{a_{\mathrm{a}}}$ is the arithmetic mean of the particle's projected area. $\overline{a_{\mathrm{a}}}$ was computed using a Monte Carlo approach. Each particle was rotated randomly in the three-dimensional space and the particle was "scanned" by rays in Z direction emerging from every single point on the X-Y plane. Counting the rays "hitting" the particle, the total projected area of the particle was computed.

\subsection{Stokes Regime}

The dependency of the drag force on the structure of the fractal aggregates in the limiting case of zero Reynolds number can be investigated by Stokesian Dynamics (SD) (Brady \& Bossis, 1988; Durlofsky et al., 1986). SD is based on the solution of the Stokes equation for a point force given by the Oseen tensor. The linearity of the Stokes equation allows the superposition of the flow disturbance caused by the point forces distributed on the surfaces of the particles. Considering the spherical structure of the primary particles, a multipole expansion of the force field is used. The general formulation of the SD includes force, torque, and stresslet (F-T-S model); and covers translational velocity, angular velocity, and rate of strain interactions. For a cluster of n primary particles, the general formulation of the SD can be presented as follows:

$$
\left[\begin{array}{c}
\overline{F_{\mathrm{n}}} \\
\overline{T_{\mathrm{n}}} \\
\overline{\overline{S_{\mathrm{n}}}}
\end{array}\right]=\mathcal{R} \cdot\left[\begin{array}{c}
\overline{U_{\mathrm{n}}}-\overline{U_{\mathrm{n}}^{\infty}}-\overline{\Omega^{\infty}} \\
-\overline{E^{\infty}}
\end{array}\right]
$$

where $\overline{F_{\mathrm{n}}}, \overline{T_{\mathrm{n}}}$, and $\overline{\overline{S_{\mathrm{n}}}}$ are the force, torque, and stresslet ${ }^{1}$ acting on the primary particles. $\overline{U_{\mathrm{n}}}$ and $\overline{\Omega_{\mathrm{n}}}$ are translational and angular velocities of the primary particles, respectively. $\overline{U^{\infty}}$ and $\overline{\Omega^{\infty}}$ are the translational and angular velocities of the far-field flow. $\overline{\overline{E^{\infty}}}$ is the rate of strain tensor of far-field flow at the centre of mass of the monomers. The number of the lines over the parameters in Eq. (3) shows the order of the tensor (however, it represents average values in the rest of the article). Finally, $\mathcal{R}$ is the grand resistance matrix which solely depends on the relative position and diameters of the primary particles.

In case of the rigid-body clusters where the relative velocities of any two primary particles are zero, the lubrication correction can be ignored (Binder et al., 2006; Harshe et al., 2010; Schlauch et al., 2013; Seto et al., 2011) and SD formulation will be reduced to F-T model. Here, the grand resistance matrix was constructed using the algorithm described by Durlofsky et al. (1986); and

\footnotetext{
${ }^{1}$ symmetric part of the first moment of the surface stress
} 
the exact two-body resistance functions of unequal primary particles suggested by Jeffrey \& Onishi (1984) and Kim \& Karrila (2013) were used.

Considering the linearity of the Stokes equations, the total drag force acting on an agglomerate is equal to the summation of the drag forces acting on its constituent primary particles. The arithmetic mean drag force acting on an individual aggregate is computed for 50 random rotations of the grand mobility matrix in the three dimensional space.

Upon the measurement of the total drag force, the mobility equivalent diameter of the aggregates in the continuum regime $\left(d_{\mathrm{m}, \mathrm{c}}\right)$ can be calculated using the following equation,

$$
d_{\mathrm{m}, \mathrm{c}}=\frac{F}{3 \pi \mu U}
$$

where $F$ is the magnitude of the drag force, $\mu$ is the dynamic viscosity of the medium, and $U$ is the relative velocity of the particle and the medium.

\section{Results and Discussion}

\subsection{Agglomerate Structure Characterization}

The average fractal dimension, $D_{\mathrm{f}}$, and prefactor, $k_{\mathrm{f}}$, of numerical agglomerates were calculated from Eq. (5):

$$
N_{\mathrm{p}}=k_{\mathrm{f}}\left(\frac{R_{\mathrm{g}}}{R_{\mathrm{pg}}}\right)^{D_{\mathrm{f}}}
$$

Here $R_{\mathrm{pg}}$ is the median radius of the primary particles; and $R_{\mathrm{g}}$ is the three-dimensional radius of gyration of the particles given by:

$$
R_{\mathrm{g}}^{2}=\frac{1}{\sum R_{i}^{3}} \sum R_{i}^{3}\left(a_{i-\mathrm{CM}}^{2}+R_{\mathrm{g}, i}^{2}\right)
$$

where $R_{i}$ is the radius of the $i^{\text {th }}$ primary particle, $a_{i-\mathrm{CM}}$ is the separation distance of the $i^{\text {th }}$ monomer from the center of the mass of the particle; and $R_{\mathrm{g}, i}$ is the radius of gyration of the $i^{\text {th }}$ primary particle $\left(R_{\mathrm{g}, i}^{2}=0.6 R_{i}^{2}\right)$.

Figure 1 shows that the average gyration diameter $\left(d_{\mathrm{g}}=2 R_{\mathrm{g}}\right)$ of the agglomerates at each $N_{\mathrm{p}}$ increases with $\sigma_{\mathrm{g}}$. Throughout this article $d_{\mathrm{pg}}$ is the median diameter of the primary particles in individual agglomerates. 


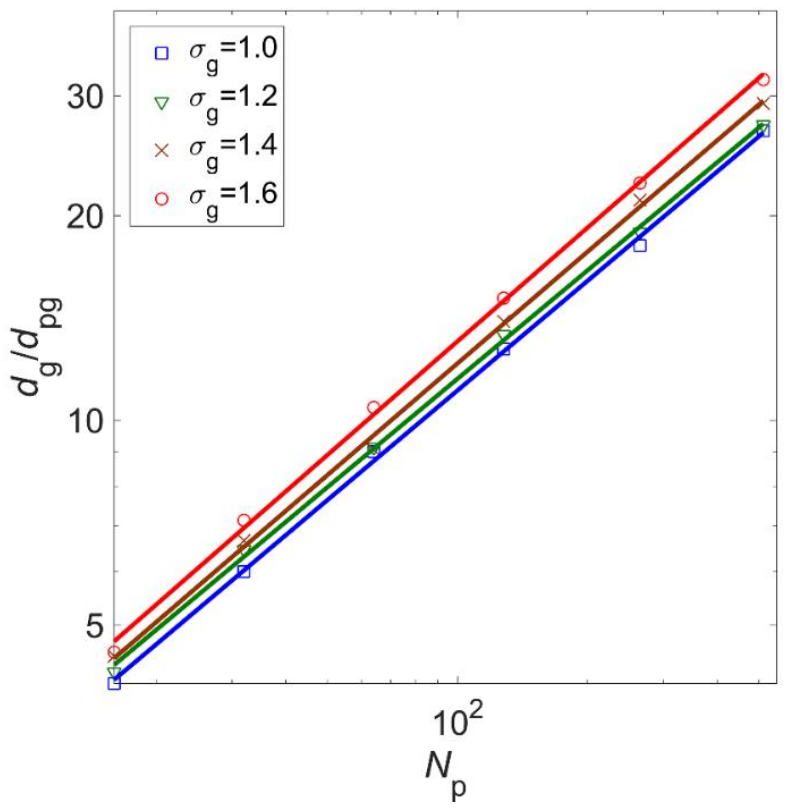

Figure 1: The effect of $\sigma_{\mathrm{g}}$ on normalized $d_{\mathrm{g}}$ in agglomerates of different size, $N_{\mathrm{p}}$.

Applying linear regression to the logarithms of $N_{\mathrm{p}}$ and $R_{\mathrm{g}} / R_{\mathrm{pg}}$ showed that the fractal dimension decreases from 1.78 to 1.73 as the primary particles polydispersity increases from 1 to 1.6 , consistent with the results obtained by Eggersdorfer \& Pratsinis (2012) for particles generated by the DLCA algorithm. However, $k_{\mathrm{f}}$ was approximately constant and equal to 1.4. Although numerical aggregates used in this study were not generated by a DLCA algorithm, their fractal structure is similar to the DLCA particles.

For the simulated aggregates, the mass and area were computed and the average values of these parameters were found to be within $1 \%$ of the expected values for lognormally distributed particles (Seinfeld \& Pandis ,2012), that is

$$
\begin{aligned}
& m_{\mathrm{agg}}=\exp \left(4.5 \ln ^{2} \sigma_{\mathrm{g}}\right) \frac{\pi}{6} \rho d_{\mathrm{pg}}^{3} N_{\mathrm{p}} \\
& s_{\mathrm{agg}}=\exp \left(2 \ln ^{2} \sigma_{\mathrm{g}}\right) \pi d_{\mathrm{pg}}^{2} N_{\mathrm{p}}
\end{aligned}
$$

These results do not depend on the structure of the aggregates, but the radius of gyration and mobility diameters do depend on structure and thus cannot be obtained analytically. The accuracy of these equations for agglomerates composed of a finite number of monomers is discussed in the next section.

\subsection{Mobility Diameter of the Fractal Agglomerates in the Free Molecular Regime}

Agglomerates of different sizes and polydispersity were projected into 50 random orientations and their projected areas were measured. Arithmetic average mobility equivalent diameter $\left(d_{\mathrm{m}, \mathrm{fm}}\right)$ is equal to the average projected-area-equivalent diameter of the particles $\left(d_{\mathrm{a}}\right)$. 
The mobility diameter in the free molecular regime can be correlated to $N_{\mathrm{p}}$ and $d_{\mathrm{pg}}$ in the following form:

$$
d_{\mathrm{a}}=d_{\mathrm{m}, \mathrm{fm}}=k_{\mathrm{m}, \mathrm{fm}} d_{\mathrm{pg}} N_{\mathrm{p}}^{D_{\mathrm{m}, \mathrm{fm}}}
$$

The normalized mobility diameter of the fractal agglomerates in the free molecular regime is plotted as a function of $N_{\mathrm{p}}$ for different $\sigma_{\mathrm{g}}$ in Figure 2 (solid lines). Variation of $d_{\mathrm{m}, \mathrm{fm}} / d_{\mathrm{pg}}$ with $\sigma_{\mathrm{g}}$ for different $N_{\mathrm{p}}$ is also illustrated in Figure S3 (online supplementary information). Regression shows that $D_{\mathrm{m}, \mathrm{fm}}$ is almost independent of $\sigma_{\mathrm{g}}$; however, $k_{\mathrm{m}, \mathrm{fm}}$ increases up to $26 \%$ when $\sigma_{\mathrm{g}}$ reaches 1.6. For simplicity, $D_{\mathrm{m}, \mathrm{fm}}$ was kept constant and equal to 0.46 and $k_{\mathrm{m}, \mathrm{fm}}$ was measured for different $\sigma_{\mathrm{g}}$ (Table 1, which also includes the continuum regime results discussed in the next section). For aggregates of monodisperse primary particles, $d_{\mathrm{m}, \mathrm{fm}}=0.97 d_{\mathrm{pg}} N_{\mathrm{p}}^{0.46}$ is within $3 \%$ deviation from $d_{\mathrm{m}, \mathrm{fm}}=d_{\mathrm{pg}} N_{\mathrm{p}}^{0.46}$ suggested in Sorensen (2011).

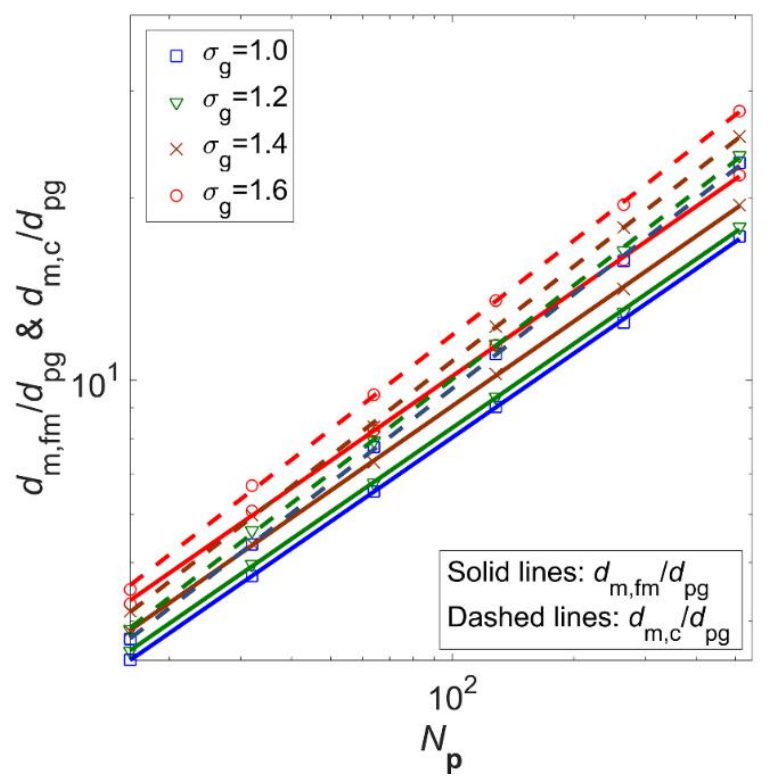

Figure 2: The effect of $\sigma_{\mathrm{g}}$ on normalized $d_{\mathrm{m}, \mathrm{fm}}$ and $d_{\mathrm{m}, \mathrm{c}}$ in agglomerates of different size, $N_{\mathrm{p}}$.

Table 1: Regression-obtained parameters for agglomerates of different polydispersity

\begin{tabular}{|c|c|c|c|c|}
\hline$\sigma_{g}$ & $D_{\mathrm{m}, \mathrm{fm}}$ & $k_{\mathrm{m}, \mathrm{fm}}$ & $D_{\mathrm{m}, \mathrm{c}}$ & $k_{\mathrm{m}, \mathrm{c}}$ \\
\hline 1.0 & 0.46 & $0.970( \pm 0.011)$ & 0.52 & $0.887( \pm 0.005)$ \\
\hline 1.2 & 0.46 & $1.006( \pm 0.010)$ & 0.52 & $0.917( \pm 0.004)$ \\
\hline 1.4 & 0.46 & $1.095( \pm 0.010)$ & 0.52 & $0.987( \pm 0.010)$ \\
\hline 1.6 & 0.46 & $1.226( \pm 0.012)$ & 0.52 & $1.086( \pm 0.005)$ \\
\hline
\end{tabular}

All fits have $\mathrm{R}^{2}>0.99$.

Variation of $k_{\mathrm{m} \text {,fm }}$ with $\sigma_{\mathrm{g}}$ can also be formulated by $k_{\mathrm{fm}}=0.94+0.03 \sigma_{\mathrm{g}}^{4.8}$ (R-square=0.99). Substituting this into Eq. (8), free molecular mobility diameter of the fractal agglomerates can be calculated using the following correlation: 


$$
d_{\mathrm{m}, \mathrm{fm}}=\left(0.94+0.03 \sigma_{\mathrm{g}}^{4.8}\right) d_{\mathrm{pg}} N_{\mathrm{p}}^{0.46}
$$

This result is numerically about $1 \%$ higher than using the surface-area-equivalent diameter, $d_{\mathrm{ps}}$, (measured from the application of Eq. 7b) in $d_{\mathrm{m}, \mathrm{fm}}=0.97 d_{\mathrm{ps}} N_{\mathrm{p}}^{0.46}$.

The relation between mobility diameter and mass (Eqs. 8 and 9) is often expressed in the inverse manner, $m \sim d_{\mathrm{m}}^{D_{\mathrm{mm}}}$ (Abegglen et al., 2015; Ghazi et al., 2013; Johnson et al., 2015; Maricq \& Xu, 2004). The normalized mass of the individual simulated aggregates (measured directly from $\sum m_{\mathrm{i}}$ where $m_{\mathrm{i}}$ is the mass of an individual monomer) is plotted as a function of the normalized free molecular mobility diameter in Figure 3 (continuum results are illustrated in Figure S4, online supplementary information). The ratio of the actual mass of the agglomerates (illustrated in Figure 3) to the masses estimated from the application of Eq. (7a) are also illustrated in Fig S5 for different normalized free molecular mobility diameters. As illustrated in Figure 3 and S4-5, aggregates with the same $N_{\mathrm{p}}$ have a wide range of mass and mobility diameters. The relative variations increase with $\sigma_{\mathrm{g}}$ and decrease with $N_{\mathrm{p}}$. These Figures also show that particles of the same mobility have a wide range of mass which cannot fully be captured by Eq. 7a. The mass-mobility exponent of particles of the same primary particle polydispersity and different $N_{\mathrm{p}}$ was determined from the slope of the lines in Figure 3. Our results showed that the mass-mobility exponent increased slightly from 2.15 to 2.23 as $\sigma_{\mathrm{g}}$ increased from 1.0 to 1.6 (substantially consistent with constant $D_{\mathrm{m}, \mathrm{fm}}$ discussed earlier). Although the present work focusses on average values of mass and mobility, Figure 3 and S4-5 show that individual aggregates can deviate substantially from the average mass-mobility relation - a fact that should be considered in models of instrument transfer functions.

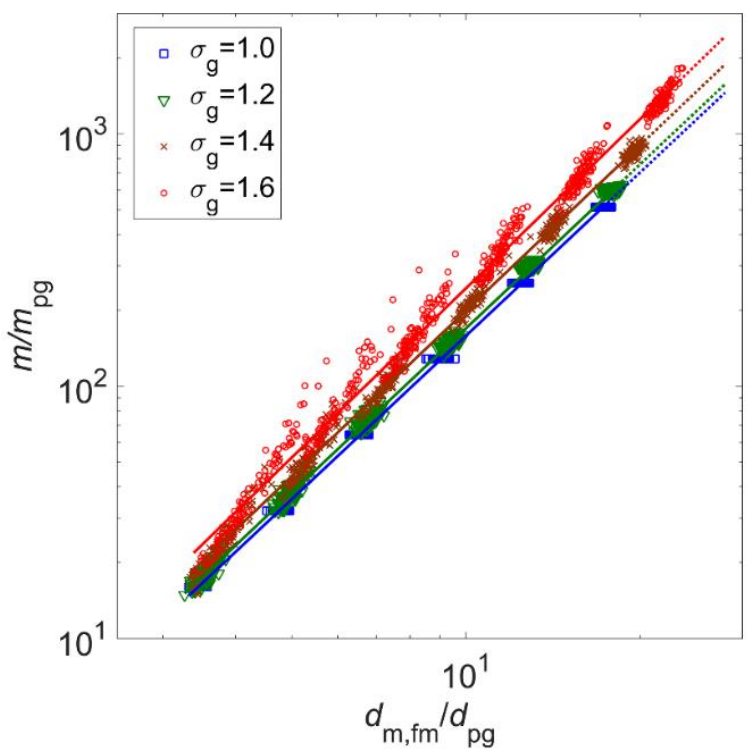

Figure 3: The effect of $\sigma_{\mathrm{g}}$ on the mass-mobility correlation of synthetic particles in the free molecular regime. Continuous lines are regressions to the data in the forms of $m / m_{\mathrm{p}}=A d_{\mathrm{m}, \mathrm{fm}}^{D_{\mathrm{m}}}$. Dotted lines are extrapolation of the fitted lines to slightly larger $d_{\mathrm{m}, \mathrm{fm}} / d_{\mathrm{pg}}$. 


\subsection{Mobility Diameter of Straight Chains and Fractal Agglomerates in the Continuum Regime}

\subsubsection{Validation of computational method}

First, SD was applied to doublets and straight chains of monodisperse primary particles (online supplementary information, Table S1). These calculations agreed with analytical results to better than 5\% - about as good as the Lattice Boltzman Method (LBM) for doublets (Binder et al., 2006). Our results for straight chains also agree to within $4 \%$ error of results reported by (Chan \& Dahneke, 1981; Filippov, 2000; Horvath, 1974) (Figure S6, online supplementary information).

Next, fractal agglomerates of monodisperse primary particles were subjected to uniform flow fields in 50 random directions and mobility-equivalent diameter was computed. Average results are plotted as a function of $N_{\mathrm{p}}$ in Figure 4; and agree well with literature (Binder et al., 2006; Filippov, 2000; Lattuada et al., 2003; Melas et al., 2014; Schlauch et al., 2013; Sorensen, 2011; Thajudeen et al., 2012). Slight discrepancies between the results could be due to the differences in the particle structures (the whole structure may not necessarily be fully captured by only $D_{\mathrm{f}}$ and $k_{\mathrm{f}}$ ), sample size and averaging artifacts, and errors in the calculation of the approximate mobility diameters.

For aggregates of monodisperse primary particles, regression yields $d_{\mathrm{m}, \mathrm{c}}=0.887 d_{\mathrm{pg}} N_{\mathrm{p}}^{0.52}$, approximately consistent with the equations suggested by Sorensen (2011).

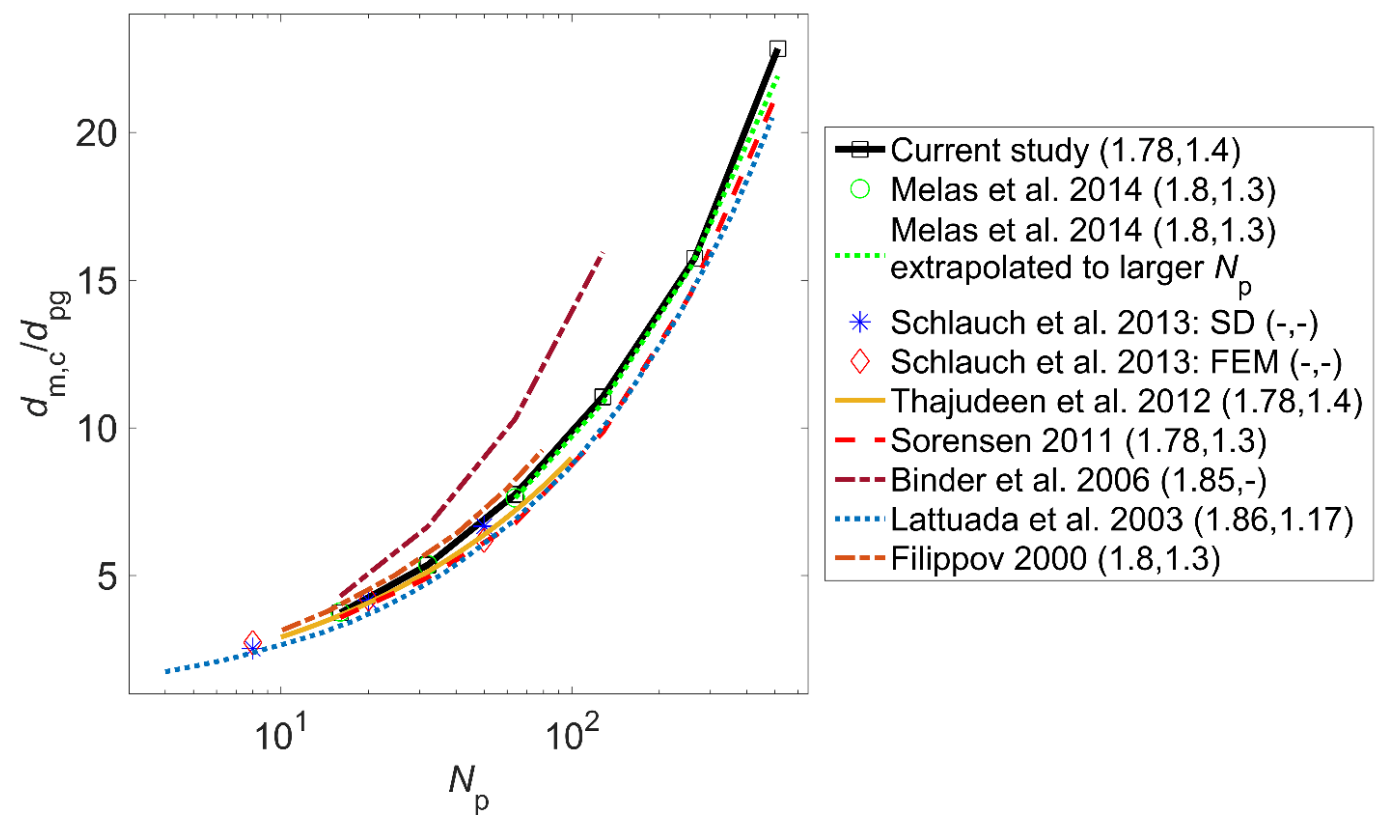

Figure 4: Variation of normalized $d_{\mathrm{m}, \mathrm{c}}$ with $N_{\mathrm{p}}$ in fractal agglomerates of monodisperse primary particles. Values in parenthesis are $\left(D_{\mathrm{f}}, k_{\mathrm{f}}\right)$.

Three-dimensional radii of gyration $R_{\mathrm{g}}$ were also calculated and the ratio of average continuum mobility radius to $R_{\mathrm{g}}$ was computed. As illustrated in Figure 5, for fractal agglomerates of monodisperse primary particles $\beta$ is $0.89 \pm 0.02$ in the range of $N_{\mathrm{p}}=64$ to 512 consistent with the values reported by Chen et al. (1987) and Meakin et al. (1985) where the Kirkwood-Riseman 
method was used. Earlier studies (Chen et al., 1987; Gwaze et al., 2006; Lattuada et al., 2003; Meakin et al., 1985; Melas et al., 2014; Rogak \& Flagan, 1990; Sorensen, 2011) suggested that the value of $\beta$ converges to a constant value as $N_{\mathrm{p}}$ increases. However, as shown in Figure 5, a relatively wide range of $\beta$ is reported in literature. These differences cannot be all attributed to the differences in the simulation models since similar methods resulted in different $\beta$ (e.g. Chen et al., 1987; Lattuada et al., 2003; Binder et al., 2006; Filippov, 2000). These differences may mainly be attributed to the differences in the structures of the fractal agglomerates used in these studies. It worth noting that the whole structure of the particles may not necessarily be fully captured by $D_{\mathrm{f}}$ and $k_{\mathrm{f}}$.

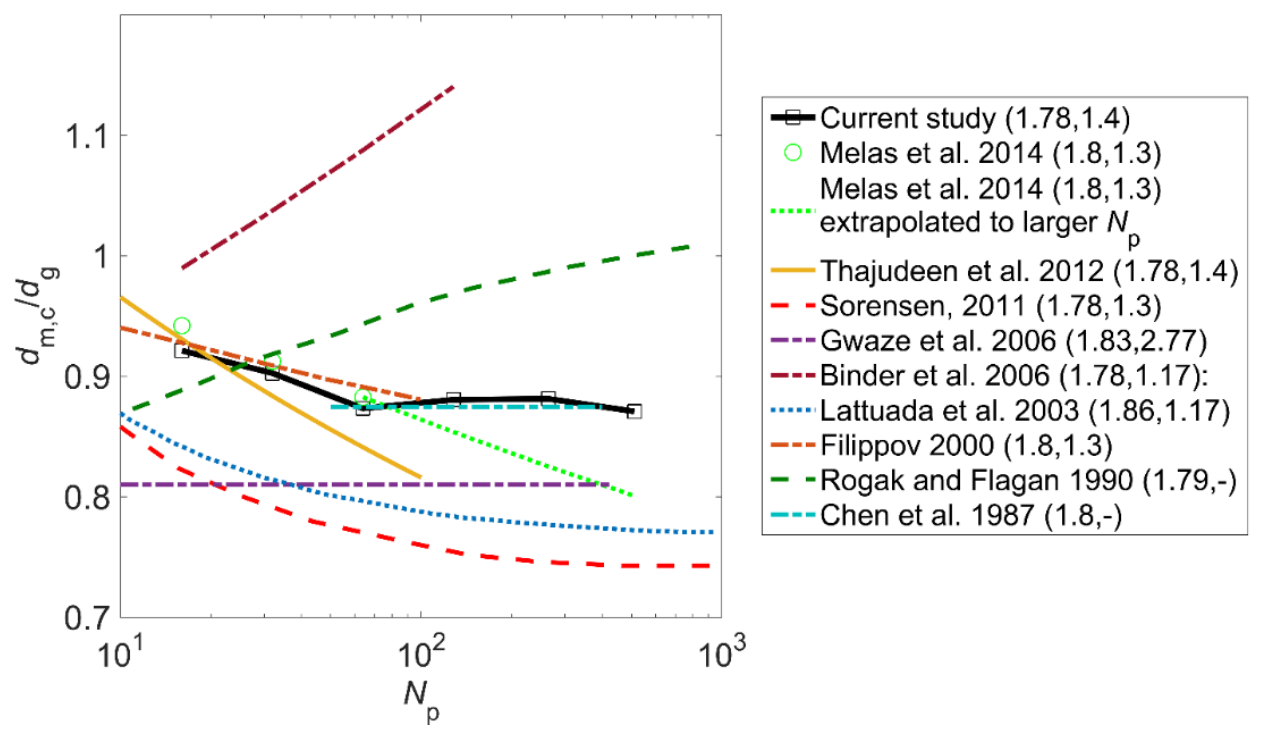

Figure 5: Variation of $R_{\mathrm{m}, \mathrm{c}} / R_{\mathrm{g}}$ with $N_{\mathrm{p}}$ in fractal agglomerates of monodisperse primary particles. Values in parenthesis are $\left(D_{\mathrm{f}}, k_{\mathrm{f}}\right)$. Results presented for (Thajudeen et al., 2012) and (Binder et al., 2006) are obtained by the authors applying Eq. (5) to the reported mobility results.

\subsubsection{Effect of primary particle polydispersity on $d_{\mathrm{m}, \mathrm{c}}$}

A correlation between the mobility equivalent diameter in continuum regime $\left(d_{\mathrm{m}, \mathrm{c}}\right)$ with total number and median diameter of the primary particles is formulated similar to the equation suggested by Sorensen (2011),

$$
d_{\mathrm{m}, \mathrm{c}}=k_{\mathrm{m}, \mathrm{c}} d_{\mathrm{pg}} N_{\mathrm{p}}^{D_{\mathrm{m}, \mathrm{c}}}
$$

Normalized continuum mobility diameter of the fractal agglomerates is plotted as a function of $N_{\mathrm{p}}$ for different $\sigma_{\mathrm{g}}$ in Figure 2 (dashed lines). Variation of normalized $d_{\mathrm{m}, \mathrm{c}}$ with $\sigma_{\mathrm{g}}$ for different $N_{\mathrm{p}}$ is also illustrated in Figure S7 (online supplementary information). As for the free molecular regime, $D_{\mathrm{m}, \mathrm{c}}$ does not change significantly with $\sigma_{\mathrm{g}}$; however, $k_{\mathrm{m}, \mathrm{c}}$ is approximately $22 \%$ higher at $\sigma_{\mathrm{g}}=1.6$ compared to $\sigma_{\mathrm{g}}=1$. For simplicity, $D_{\mathrm{m}, \mathrm{c}}$ was kept constant and equal to 0.52 and $k_{\mathrm{m}, \mathrm{c}}$ was measured for different $\sigma_{\mathrm{g}}$ (Table 1 ). 
Variation of $k_{\mathrm{m}, \mathrm{c}}$ with $\sigma_{\mathrm{g}}$ can be formulated as $k_{\mathrm{m}, \mathrm{c}}=0.85+0.03 \sigma_{\mathrm{g}}^{4.4}$ (R-square=0.99). Substituting this into Eq. (10), the average continuum mobility diameter is

$$
d_{\mathrm{m}, \mathrm{c}}=\left(0.85+0.03 \sigma_{\mathrm{g}}^{4.4}\right) d_{\mathrm{pg}} N_{\mathrm{p}}^{0.52}
$$

The influence of the primary particle polydispersity on $\beta=R_{\mathrm{m}, \mathrm{c}} / R_{\mathrm{g}}$ was also investigated. Our results show that, although both $R_{\mathrm{m}, \mathrm{c}}$ and $R_{\mathrm{g}}$ increase with $\sigma_{\mathrm{g}}$, their ratio $\beta$ increases by only $3 \%$ as $\sigma_{\mathrm{g}}$ increases from 1 to 1.6 (Table 2).

Table 2: Variation of average $\beta$ with primary particle polydispersity.

\begin{tabular}{|c|c|c|c|c|}
\hline$\sigma_{g}$ & 1.0 & 1.2 & 1.4 & 1.6 \\
\hline$\beta$ & $0.89( \pm 0.02)^{*}$ & $0.88( \pm 0.02)$ & $0.90( \pm 0.03)$ & $0.92( \pm 0.04)$ \\
\hline
\end{tabular}

${ }^{*}$ values in parenthesis are the standard deviations.

The influence of the primary particle polydispersity on the mobility of agglomerates fully aligned in an external flow field, i.e. differential mobility analyzer, was also investigated. As shown in Figure S8 (online supplementary information), the ratio of the mobility diameter of particles aligned in an external field to their orientation-averaged mobility diameter is approximately independent of the primary particle polydispersity.

\subsection{Effect of "internal" and "external" mixing of primary particle size variations on the mass of the mobility-classified particles}

Dastanpour \& Rogak (2014) found that the ensemble-based geometric standard deviation of the primary particle size distribution ${ }^{1}, \sigma_{\mathrm{g}, \mathrm{ens}}$, is typically about 1.4 while it is less than 1.4 for individual agglomerates in the same ensemble $\left(\sigma_{\mathrm{g} \text {,agg }}<1.4\right)$. This means that, much of the primary particle size variation is "externally mixed". Here, we consider the implications of this in a hypothetical experiment in which particles are classified based on their mobility. For a constant ensemble-based geometric standard deviation of $\sigma_{\mathrm{g}, \text { ens }}=1.4$ and geometric mean primary particle size $\left(d_{\mathrm{pg}, \mathrm{ens}}\right)$, three different cases are considered here (Figure 6):

I. Individual agglomerates are composed of monodisperse primaries $\left(\sigma_{\mathrm{g} \text {,agg }}=1.0\right)$ and primary particle size variations are "externally mixed" ( $d_{\mathrm{pg}}$ is not similar in different agglomerates); here it is simulated with two distinct agglomerate types such that $\sigma_{\mathrm{g}, \mathrm{ens}}=$ 1.4 .

II. Individual agglomerates are composed of polydisperse primaries with $\sigma_{\mathrm{g}, \mathrm{agg}}=1.325^{2}$; but primary particle size variations are "internally mixed" ( $d_{\mathrm{pg}}$ is similar for all agglomerates of the same mobility); this is effectively the situation considered in the previous sections of this paper.

\footnotetext{
${ }^{1}$ Geometric standard deviation of all primary particles regardless of the agglomerates they belong to.

${ }^{2} \sigma_{\mathrm{g} \text {,agg }}$ and $\sigma_{\mathrm{g}, \mathrm{ens}}$ cannot be exactly equal.
} 
III. Individual agglomerates are composed of polydisperse primaries with $\sigma_{\mathrm{g} \text {,agg }}=1.2$ and $d_{\mathrm{pg}}$ varies between agglomerates (it changes in a way that $\sigma_{\mathrm{g}, \mathrm{ens}}=1.4$ ).



Figure 6: Different sets of agglomerates having the same ensemble-average primary particle polydispersity $\left(\sigma_{\mathrm{g}, \mathrm{ens}}=1.4\right)$. Red circles are centered at the center of mass of the particles, with diameters equal to $d_{\mathrm{m}, \mathrm{fm}}$ of the particles.

Depending on the situation, each of these cases may be observed in practice. Case III is the most realistic case for soot particles (Dastanpour \& Rogak, 2014).

Figure 7 illustrates the variation of normalized mass with free molecular mobility diameter of mixtures of aggregates according to the 3 cases. Mobility classification corresponds to a vertical line on the graph. Continuum mobility results are excluded for simplicity. Comparing case I with Case II, agglomerates of the same mobility diameter have $20.2 \pm 3 \%$ and $24.4 \pm 3 \%$ smaller mass in the free molecular and continuum regimes, respectively. Case III is between Cases I and II.

The importance of discriminating between $\sigma_{\mathrm{g} \text {,agg }}$ and $\sigma_{\mathrm{g} \text {,ens }}$ in simulations and analysis of experimental data is further elaborated in Table 3 for a hypothetical mobility classification experiment. For each case, more than a thousand agglomerates were generated; a lognormal size distribution was assumed for the ensembles of the primary particles; and the geometric mean monomer diameter of each individual agglomerate was selected from this distribution.

Normalized free molecular and continuum mobility diameters of the size classified particles were set to 5 in the simulated experiment. Table 3 also reports geometric mean number of the primary particles in individual agglomerates and normalized mass $\left(m / m_{\text {pg,ens }}\right.$, where $m_{\text {pg,ens }}$ is the mass of the median-diameter particle $d_{\mathrm{pg} \text {,ens }}$ considering all primaries in the whole ensemble of the

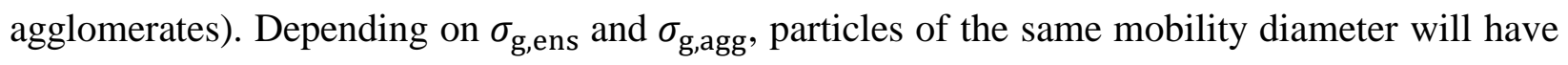
significantly different median $N_{\mathrm{p}}$ and $\mathrm{m} / \mathrm{m}_{\mathrm{pg} \text {,ens }}$. These results elaborate that the differences 
between $\sigma_{\mathrm{g} \text {,ens }}$ and $\sigma_{\mathrm{g} \text {,agg }}$ should be considered and appropriate values of these parameters should be used in the simulations and interpretation of the experimental data.



Figure 7: Variation of normalized $m_{\mathrm{p}}$ with $d_{\mathrm{m}, \mathrm{fm}}$ for three polydispersity cases.

Table 3: Effect of $\sigma_{\mathrm{g}, \text { agg }}$ and $\sigma_{\mathrm{g}, \text { ens }}$ on median $N_{\mathrm{p}}$ and $m / m_{\mathrm{pg}, \text { ens }}$ for a hypothetical mobility classification experiment.

\begin{tabular}{|c|c|c|c|c|c|c|c|}
\cline { 5 - 8 } \multicolumn{2}{c|}{} & \multicolumn{2}{c|}{ Free molecular regime } & \multicolumn{2}{c|}{ Continuum regime } \\
\hline Case & $\sigma_{\mathrm{g}, \text { agg }}$ & $\sigma_{\mathrm{g}, \text { ens }}$ & $d_{\mathrm{m}} / d_{\mathrm{pg} \text {,ens }}$ & $N_{\mathrm{p}}$ & $m / m_{\mathrm{pg}, \text { ens }}$ & $N_{\mathrm{p}}$ & $m / m_{\mathrm{pg}, \text { ens }}$ \\
\hline I & 1.0 & 1.4 & 5 & 35 & 35.19 & 28 & 28.10 \\
\hline II & 1.4 & 1.4 & 5 & 27 & 42.29 & 23 & 34.96 \\
\hline III & 1.2 & 1.4 & 5 & 32 & 38.26 & 26 & 31.34 \\
\hline
\end{tabular}

\section{Conclusion}

For a fixed number of monomers $N_{\mathrm{p}}$ and median primary particle diameter $d_{\mathrm{pg}}$, the physical size of the aggregate increases substantially with primary particle polydispersity $\sigma_{\mathrm{g}}$. Arithmetic average primary particle diameter, surface area, and total mass of aggregates increase with $\sigma_{\mathrm{g}}$. Consequently, the effect of primary particle polydispersity should be considered carefully in the analysis of transmission electron micrographs or combined mass and electron microscopy analysis. Correlations are developed here to link number, size, and polydispersity of the primary particles to the surface area, mass, and projected area of the fractal agglomerates.

The first effect of primary particle polydispersity on mobility diameter is simply that the physical size of the aggregate increases with polydispersity. This effect can be substantial $(\sim 26 \%)$ in the free molecule regime for $\sigma_{\mathrm{g}}=1.6$ and $N_{\mathrm{p}}=512$; in this regime we cannot say whether or not primary particle size variation has any effect other than the geometric one described above, for we have 
assumed that the arithmetic average mobility equivalent diameter is equal to the average projectedarea-equivalent diameter of the particle.

In the continuum regime, we have used Stokesian Dynamics computations that should be capable of resolving the effect of structure accurately. As for the free molecular regime, the mobility diameter of fractal agglomerates increases with primary particle polydispersity in the continuum regime. This effect can be substantial ( $23 \%)$ in this regime for $\sigma_{\mathrm{g}}=1.6$ and $N_{\mathrm{p}}=512$. Nearly all of this effect is due to the change in radius of gyration; the average ratio $\beta=R_{\mathrm{m}, \mathrm{c}} / R_{\mathrm{g}}$ increases by $\sim 3 \%$ as $\sigma_{\mathrm{g}}$ increases from 1 to 1.6 . We have found that the considerable variation of $d_{\mathrm{m}, \mathrm{c}} / d_{\mathrm{g}}$ in the literature cannot all be ascribed to calculation or measurement error: different cluster aggregation mechanisms yield different structures that affect $d_{\mathrm{m}, \mathrm{c}} / d_{\mathrm{g}}$. Correlations are derived for the estimation of the mobility diameter based on the size, number, and polydispersity of the primary particles in fractal agglomerates in both free molecular and continuum regimes.

It is shown that particles of the same fractal structure and number of monomers may have different mass and mobility diameter. The spread of the mass and mobility distributions increase with primary particle polydispersity while the mass-mobility exponent is not strongly affected by $\sigma_{\mathrm{g}}$.

Having developed models for the mobility of fractal aggregates it is possible to consider the implication of primary particle size variability in experiments, e.g. when mass and optical properties are estimated for mobility classified particles. It is important to discriminate between the variations of the primary particle diameters within individual agglomerates and the variations within ensembles of aggregates.

\section{References}

Abegglen, M., Durdina, L., Brem, B. T., Wang, J., Rindlisbacher, T., Corbin, J. C., ... Sierau, B. (2015). Effective density and mass-mobility exponents of particulate matter in aircraft turbine exhaust: Dependence on engine thrust and particle size. Journal of Aerosol Science, 88, 135-147. doi: $10.1016 /$ j.jaerosci.2015.06.003

Binder, C., Feichtinger, C., Schmid, H., Thürey, N., Peukert, W., \& Rüde, U. (2006). Simulation of the hydrodynamic drag of aggregated particles. Journal of Colloid and Interface Science, 301(1), 155-67. doi: 10.1016/j.jcis.2006.04.045

Binder, C., Hartig, M. a J., \& Peukert, W. (2009). Structural dependent drag force and orientation prediction for small fractal aggregates. Journal of Colloid and Interface Science, 331(1), 243-50. doi: 10.1016/j.jcis.2008.11.021

Boies, A. M., Stettler, M. E. J., Swanson, J. J., Johnson, T. J., Olfert, J. S., Johnson, M., .. Rogak, S. N. (2015). Particle Emission Characteristics of a Gas Turbine with a Double Annular Combustor. Aerosol Science and Technology, 49(9), 842-855. doi: 10.1080/02786826.2015.1078452

Bossis, G., Meunier, A., \& Brady, J. F. (1991). Hydrodynamic stress on fractal aggregates of spheres. The Journal of Chemical Physics. 
Botet, R., Jullien, R., \& Kolb, M. (1984). Hierarchical model for irreversible kinetic cluster formation. Physics A: Mathematical and General, 17(2), 75-79. doi: 10.1088/0305-4470/17/2/009

Brady, J. F., \& Bossis, G. (1988). Stokesian Dynamics. Annual Review of Fluid Mechanics, 20(1), 111-157. doi: 10.1146/annurev.fl.20.010188.000551

Chan, P., \& Dahneke, B. (1981). Free-molecule drag on straight chains of uniform spheres. Journal of Applied Physics, 52(5), 3106. doi: 10.1063/1.329173

Chen, Z.-Y., Meakin, P., \& Deutch, J. (1987). Comment on "'Hydrodynamic behavior of fractal aggregates." Physical Review Letters, 59(18), 2121-2121. doi: 10.1103/PhysRevLett.59.2121

Dankers, S., \& Leipertz, A. (2004). Determination of Primary Particle Size Distributions from Time-Resolved Laser-Induced Incandescence Measurements. Applied Optics, 43(18), 3726. doi: 10.1364/AO.43.003726

Dastanpour, R., \& Rogak, S. N. (2014). Observations of a correlation between primary particle and aggregate size for soot particles. Aerosol Science and Technology, 48(10), 1043-1049. doi: $10.1080 / 02786826.2014 .955565$

Douglas, J. F., Zhou, H.-X., \& Hubbard, J. B. (1994). Hydrodynamic friction and the capacitance of arbitrarily shaped objects. Physical Review E, 49(6), 5319-5331. doi: 10.1103/PhysRevE.49.5319

Durlofsky, L., Brady, J. F., \& Bossis, G. (1986). Dynamic simulation of hydrodynamically interacting particles. Journal of Fluid Mechanics, 180, 21-49. doi: 10.1017/S002211208700171X

Eggersdorfer, M. L., \& Pratsinis, S. E. (2012). The structure of agglomerates consisting of polydisperse particles. Aerosol Science and Technology: The Journal of the American Association for Aerosol Research, 46(3), 347-353. doi: 10.1080/02786826.2011.631956

Eggersdorfer, M. L., \& Pratsinis, S. E. (2013). Restructuring of aggregates and their primary particle size distribution during sintering. AIChE Journal, 59(4), 1118-1126. doi: 10.1002/aic. 14043

Filippov, A. (2000). Drag and Torque on Clusters of N Arbitrary Spheres at Low Reynolds Number. Journal of Colloid and Interface Science, 229(1), 184-195. doi: 10.1006/jcis.2000.6981

Ghazi, R., Tjong, H., Soewono, A., Rogak, S. N., \& Olfert, J. S. (2013). Mass, Mobility, Volatility, and Morphology of Soot Particles Generated by a McKenna and Inverted Burner. Aerosol Science and Technology, 47(4), 395-405. doi: 10.1080/02786826.2012.755259

Gmachowski, L. (2007). Hydrodynamics of aggregates with mixed statistics. Colloids and Surfaces A: Physicochemical and Engineering Aspects, 295(1-3), 34-37. doi: 10.1016/j.colsurfa.2006.08.026

Gopalakrishnan, R., Thajudeen, T., \& Hogan Jr, C. J. (2011). Collision limited reaction rates for arbitrarily shaped particles across the entire diffusive Knudsen number range. The Journal of Chemical Physics, 135(5), 054302. doi: 10.1063/1.3617251 
Graves, B., Olfert, J., Patychuk, B., Dastanpour, R., \& Rogak, S. (2015). Characterization of Particulate Matter Morphology and Volatility from a Compression-Ignition Natural-Gas DirectInjection Engine. Aerosol Science and Technology, 49(8), 589-598. doi: 10.1080/02786826.2015.1050482

Gwaze, P., Schmid, O., Annegarn, H. J., Andreae, M. O., Huth, J., \& Helas, G. (2006). Comparison of three methods of fractal analysis applied to soot aggregates from wood combustion. Journal of Aerosol Science, 37(7), 820-838. doi: 10.1016/j.jaerosci.2005.06.007

Hansen, J., \& Nazarenko, L. (2004). Soot climate forcing via snow and ice albedos. Proceedings of the National Academy of Sciences of the United States of America, 101(2), 423-8. doi: 10.1073/pnas.2237157100

Harada, S., Tanaka, R., Nogami, H., \& Sawada, M. (2006). Dependence of fragmentation behavior of colloidal aggregates on their fractal structure. Journal of Colloid and Interface Science, 301(1), 123-9. doi: 10.1016/j.jcis.2006.04.051

Harshe, Y. M., Ehrl, L., \& Lattuada, M. (2010). Hydrodynamic properties of rigid fractal aggregates of arbitrary morphology. Journal of Colloid and Interface Science, 352(1), 87-98. doi: 10.1016/j.jcis.2010.08.040

Heine, M. C., \& Pratsinis, S. E. (2007). Polydispersity of primary particles in agglomerates made by coagulation and sintering. Journal of Aerosol Science, 38(1), 17-38. doi: 10.1016/j.jaerosci.2006.09.005

Horvath, H. (1974). The sedimentation behavior of non-spherical particles. Staub Reinhalt. Reinhalt. Luft, 34, 197-202.

Ichiki, K., Kobryn, A. E., \& Kovalenko, A. (2013). Resistance functions for two unequal spheres in linear flow at low Reynolds number with the Navier slip boundary condition. arXiv Preprint arXiv:1302.0461, 1-21.

Jeffrey, B. D. J., \& Onishi, Y. (1984). The forces and couples acting on two nearly touching spheres in low-Reynolds-number flow. Zeitschrift Für Angewandte Mathematik Und Physik ZAMP, 35(5), 634-641.

Jeffrey, D. J., \& Onishi, Y. (1984). Calculation of the resistance and mobility functions for two unequal rigid spheres in low-Reynolds-number flow. Journal of Fluid Mechanics, 139(-1), 261. doi: $10.1017 / \mathrm{S} 0022112084000355$

Johnson, C. P., Li, X., \& Logan, B. E. (1996). Settling Velocities of Fractal Aggregates. Environmental Science \& Technology, 30(6), 1911-1918. doi: 10.1021/es950604g

Johnson, T. J., Olfert, J. S., Symonds, J. P. R., Johnson, M., Rindlisbacher, T., Swanson, J. J., ... Wang, J. (2015). Effective Density and Mass-Mobility Exponent of Aircraft Turbine Particulate Matter. Journal of Propulsion and Power, 31(2), 573-582. doi: 10.2514/1.B35367

Kim, A. S., \& Yuan, R. (2005). Hydrodynamics of an ideal aggregate with quadratically increasing 
permeability. Journal of Colloid and Interface Science, 285(2), 627-633. doi: 10.1016/j.jcis.2004.12.009

Kim, S., \& Karrila, S. J. (2013). Microhydrodynamics: Principles and Selected Applications. Courier Corporation.

Kirkwood, J. G., \& Riseman, J. (1948). The Intrinsic Viscosities and Diffusion Constants of Flexible Macromolecules in Solution. The Journal of Chemical Physics, 16(6), 565. doi: $10.1063 / 1.1746947$

Lattuada, M., Wu, H., \& Morbidelli, M. (2003). Hydrodynamic radius of fractal clusters. Journal of Colloid and Interface Science, 268(1), 96-105. doi: 10.1016/j.jcis.2003.07.028

Liu, F., Stagg, B. J., Snelling, D. R., \& Smallwood, G. J. (2006). Effects of primary soot particle size distribution on the temperature of soot particles heated by a nanosecond pulsed laser in an atmospheric laminar diffusion flame. International Journal of Heat and Mass Transfer, 49(3-4), 777-788. doi: 10.1016/j.jijheatmasstransfer.2005.07.041

Mackowski, D. W. (2006). Monte Carlo simulation of hydrodynamic drag and thermophoresis of fractal aggregates of spheres in the free-molecule flow regime. Journal of Aerosol Science, 37(3), 242-259. doi: 10.1016/j.jaerosci.2004.11.011

Maricq, M. M., \& Xu, N. (2004). The effective density and fractal dimension of soot particles from premixed flames and motor vehicle exhaust. Journal of Aerosol Science, 35(10), 1251-1274. doi: 10.1016/j.jaerosci.2004.05.002

Meakin, P., Chen, Z.-Y., \& Deutch, J. M. (1985). The translational friction coefficient and time dependent cluster size distribution of three dimensional cluster-cluster aggregationa),b). The Journal of Chemical Physics, 82(8), 3786. doi: 10.1063/1.448890

Melas, A. D., Isella, L., Konstandopoulos, A. G., \& Drossinos, Y. (2014). Morphology and mobility of synthetic colloidal aggregates. Journal of Colloid and Interface Science, 417, 27-36. doi: 10.1016/j.jcis.2013.11.024

Peretz, A., Kaufman, J. D., Trenga, C. A., Allen, J., Carlsten, C., Aulet, M. R., ... Sullivan, J. H. (2008). Effects of diesel exhaust inhalation on heart rate variability in human volunteers. Environmental Research, 107(2), 178-84. doi: 10.1016/j.envres.2008.01.012

Rogak, S. N., \& Flagan, R. C. (1990). Stokes drag on self-similar clusters of spheres. Journal of Colloid and Interface Science, 134(1), 206-218. doi: 10.1016/0021-9797(90)90268-S

Rogak, S. N., Flagan, R. C., \& Nguyen, H. V. (1993). The mobility and structure of aerosol agglomerates. Aerosol Science and Technology, 18(1), 25-47. doi: 10.1080/02786829308959582

Rosner, D. E., \& Tandon, P. (1994). Prediction and correlation of accessible area of large multiparticle aggregates. AIChE Journal, 40(7), 1167-1182. doi: 10.1002/aic.690400708

Schlauch, E., Ernst, M., Seto, R., Briesen, H., Sommerfeld, M., \& Behr, M. (2013). Comparison of three simulation methods for colloidal aggregates in Stokes flow: Finite elements, lattice 
Boltzmann and Stokesian dynamics. Computers \& Fluids, 86, 199-209. doi: 10.1016/j.compfluid.2013.07.005

Seinfeld, J. H., \& Pandis, S. N. (2012). Atmospheric Chemistry and Physics: From Air Pollution to Climate Change. John Wiley \& Sons.

Seto, R., Botet, R., \& Briesen, H. (2011). Hydrodynamic stress on small colloidal aggregates in shear flow using Stokesian dynamics. Physical Review E, 84(4), 041405. doi: 10.1103/PhysRevE.84.041405

Sorensen, C. M. (2011). The mobility of fractal aggregates: a review. Aerosol Science and Technology, 45(7), 765-779. doi: 10.1080/02786826.2011.560909

Thajudeen, T., Gopalakrishnan, R., \& Hogan Jr, C. J. (2012). The Collision Rate of Nonspherical Particles and Aggregates for all Diffusive Knudsen Numbers. Aerosol Science and Technology, 46(11), 1174-1186. doi: 10.1080/02786826.2012.701353

Thajudeen, T., Jeon, S., \& Hogan Jr, C. J. (2015). The mobilities of flame synthesized aggregates/agglomerates in the transition regime. Journal of Aerosol Science, 80, 45-57. doi: 10.1016/j.jaerosci.2014.11.003

Ulrich, R., Iglberger, K., \& Th, N. (2008). Simulation of moving particles in 3D with the Lattice Boltzmann method, 55, 1461-1468. doi: 10.1016/j.camwa.2007.08.022

Wang, G. M., \& Sorensen, C. M. (1999). Diffusive mobility of fractal aggregates over the entire Knudsen number range. Physical Review. E, Statistical Physics, Plasmas, Fluids, and Related Interdisciplinary Topics, 60(3), 3036-44.

Wiltzius, P. (1987). Hydrodynamic behavior of fractal aggregates. Physical Review Letters, 58(7), 710-713. doi: 10.1103/PhysRevLett.58.710

Wu, Y., Cheng, T., Zheng, L., \& Chen, H. (2015). A Study of Optical Properties of Soot Aggregates Composed of Poly-Disperse Monomers Using the Superposition T-Matrix Method. Aerosol Science and Technology, 49(10), 941-949. doi: 10.1080/02786826.2015.1083938

Zhang, C., Thajudeen, T., Larriba, C., Schwartzentruber, T. E., \& Hogan Jr, C. J. (2012). Determination of the Scalar Friction Factor for Nonspherical Particles and Aggregates Across the Entire Knudsen Number Range by Direct Simulation Monte Carlo (DSMC). Aerosol Science and Technology, 46(10), 1065-1078. doi: 10.1080/02786826.2012.690543 


\title{
Supplemental Information
}

\section{The Effect of Primary Particle Polydispersity on the Morphology and Mobility Diameter of the Fractal Agglomerates in Different Flow Regimes}

\author{
Ramin Dastanpour ${ }^{1, a}$ and Steven N. Rogak ${ }^{1}$, \\ ${ }^{1}$ Department of Mechanical Engineering, University of British Columbia \\ 6250 Applied Sciences Lane, Vancouver, BC, Canada, V6T $1 Z 4$ \\ ${ }^{a}$ Corresponding author: e-mail: r.dastanpour@alumni.ubc.ca; Fax: +1-604-822-2403
}




\section{Comparison of normal and lognormal fits to experimentally measured primary particle size distributions}

The main article computes the mobility of aggregates composed of lognormally distributed primary particles. The justification of the lognormal assumption is presented here. Primary particle size distributions were measured for different operating conditions of two types of reciprocating engines: High Pressure Direct Injection (HPDI) natural gas compression-ignition engine operating with Westport Innovations HPDI natural gas combustion system, and Gasoline Direct Injection (GDI) engine. Detailed description of the experiments and operating conditions are available in (Dastanpour et al., 2015; Graves et al., 2015). For the purpose of this study, three and four operating conditions were selected randomly for HPDI and GDI engines, respectively. For each operating condition an average of 600 primary particle diameters were measured manually from the images produced by transmission electron microscopy.

Three approaches were used for the comparison of the accuracy of the normal and lognormal fits to the primary particle size distributions. First, mean and median of $d_{\mathrm{p}}$ and $\log \left(d_{p}\right)$ were compared. Primary particles are normally distributed if mean and median of $d_{\mathrm{p}}$ are equal, and lognormally distributed if mean and median of $\log \left(d_{p}\right)$ are equal. Our image processing results showed that the mean and median of $d_{\mathrm{p}}$ were approximately $6 \%$ different while mean and median of $\log \left(d_{p}\right)$ were equal $\left(O\left(10^{-3}\right)\right)$. Second, normal and lognormal distributions were fitted to the primary particle size distributions and Root Mean Square Errors (RMSE) of the fits were measured. Our results showed that the normal distributions have approximately $20 \%$ higher RMSE. Finally, Empirical Cumulative Distribution Functions (ECDF) were measured for $d_{p}$ and $\log \left(d_{p}\right)$ and compared with ECDF of a standardized normally distributed data set (Figure S1 and Figure S2). For simplicity, only four operating conditions are plotted here.

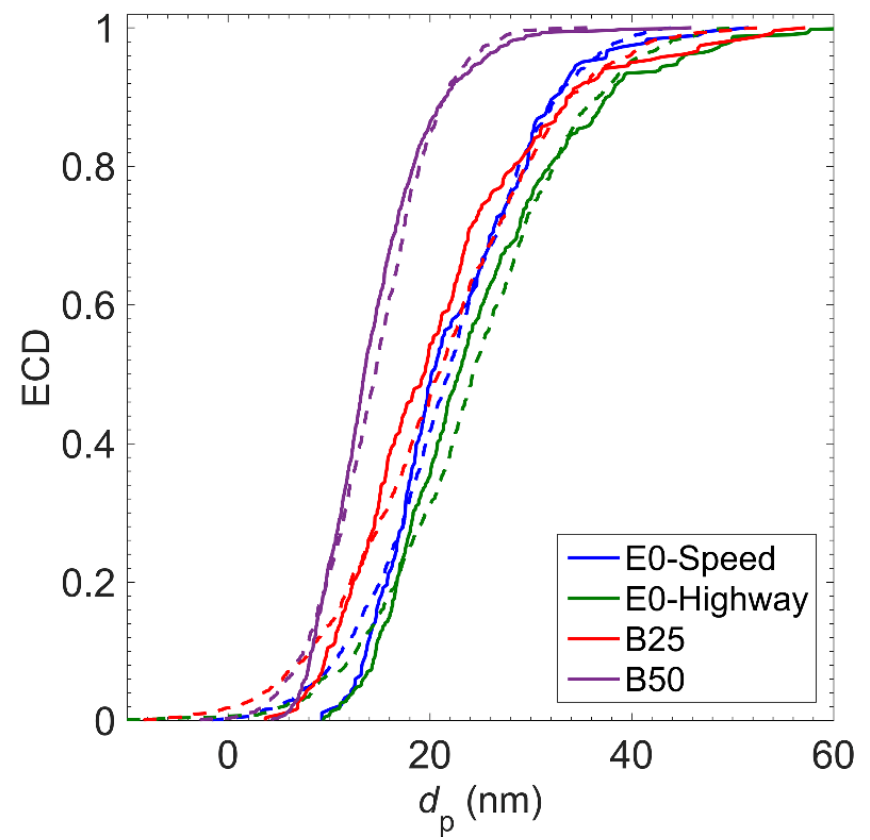

Figure S1: ECD of the size distributions of $d_{p}$ for different operating conditions. Continuous lines are for actual data while dashed lines represent ECD for a standardized normally distributed data. 


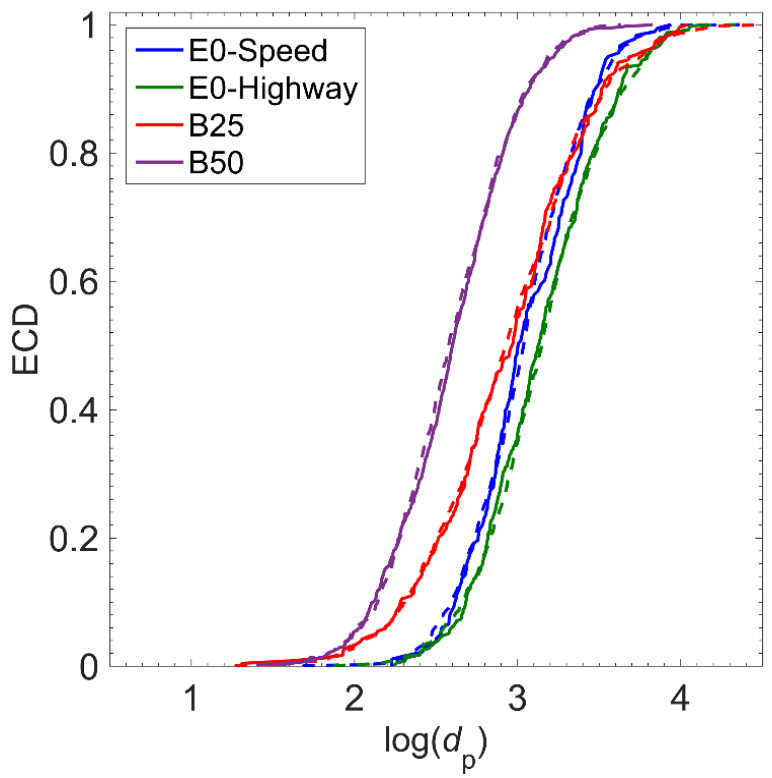

Figure $S 2$ : ECD of the size distributions of $\log \left(d_{p}\right)$ for different operating conditions. Continuous lines are for actual data while dashed lines represent ECD for a standardized normally distributed data.

As illustrated, the difference between the ECD of $\log \left(d_{\mathrm{p}}\right)$ and the standardized normally distributed data is smaller compared to the ECD of $d_{\mathrm{p}}$.

Considering the results provided here and in literature (Boies et al., 2015; Dankers \& Leipertz, 2004; Dastanpour \& Rogak, 2014; Graves et al., 2015; Johnson et al., 2015; Liu et al., 2006; Wu et al., 2015), the assumption of a lognormal size distribution for the primary particle diameter was used in this study.

\section{Effect of primary particle polydispersity on free molecular mobility diameter}

Variation of the normalized free molecular mobility diameter of fractal agglomerates, $d_{\mathrm{m}, \mathrm{fm}} / d_{\mathrm{pg}}$, with $\sigma_{\mathrm{g}}$ is illustrated in Figure $\mathrm{S} 3$. Although $d_{\mathrm{pg}}$ is nearly constant for different $\sigma_{\mathrm{g}}$, the mobility diameter of the particles increases with polydispersity. This increase in about $27 \%$ at $\sigma_{\mathrm{g}}=1.6$.

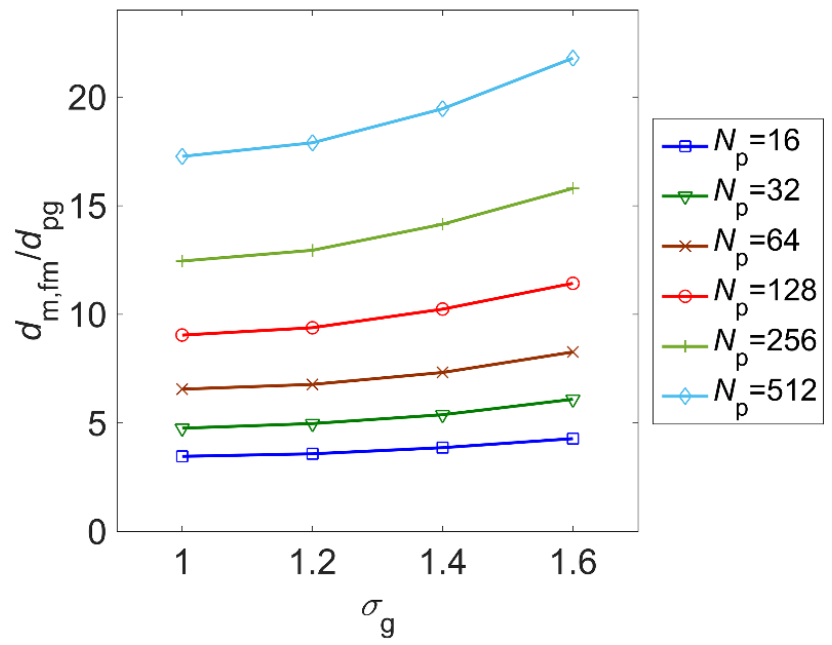

Figure S3: Variation of normalized $d_{\mathrm{m}, \mathrm{fm}}$ with $\sigma_{\mathrm{g}}$ in aggregates of different sizes. 


\section{Effect of primary particle polydispersity on mass-mobility correlation in the continuum regime}

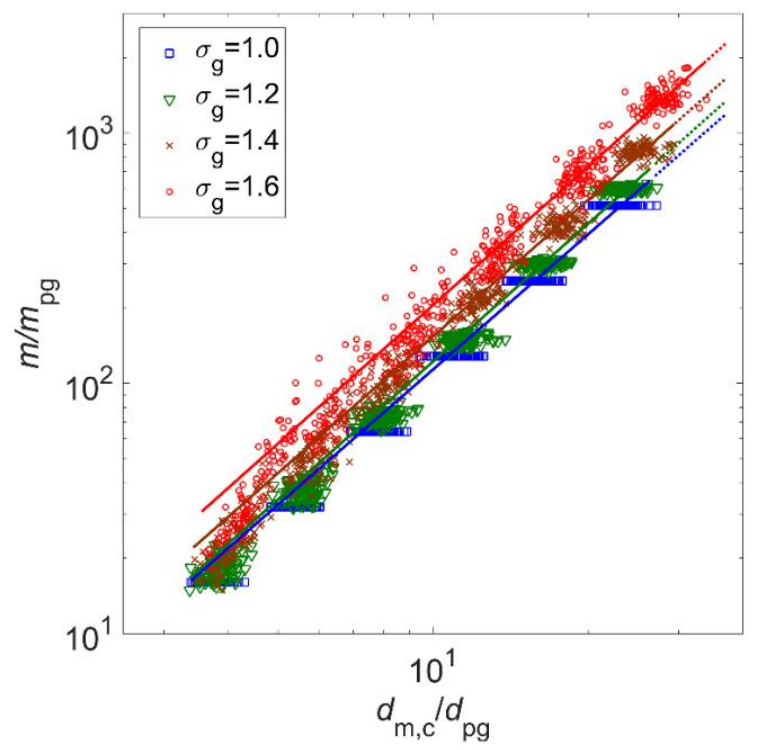

Figure S4: The effect of $\sigma_{\mathrm{g}}$ on the mass-mobility correlation of synthetic particles in the continuum regime. Continuous lines are regressions to the data in the forms of $m / m_{\mathrm{p}}=A d_{\mathrm{m}, \mathrm{c}}^{D_{\mathrm{m}}}$. Dotted lines are extrapolation of the fitted lines to slightly larger $d_{\mathrm{m}, \mathrm{c}} / d_{\mathrm{pg}}$.

\section{Comparison of actual and approximate masses of particles of different primary particle polydispersity for different normalized free molecular mobility diameters}

Actual mass of an individual agglomerate was measured from the summation of the masses of its constituting primary particles, while its approximate mass is measured from the application of Eq. 7 a (main article).

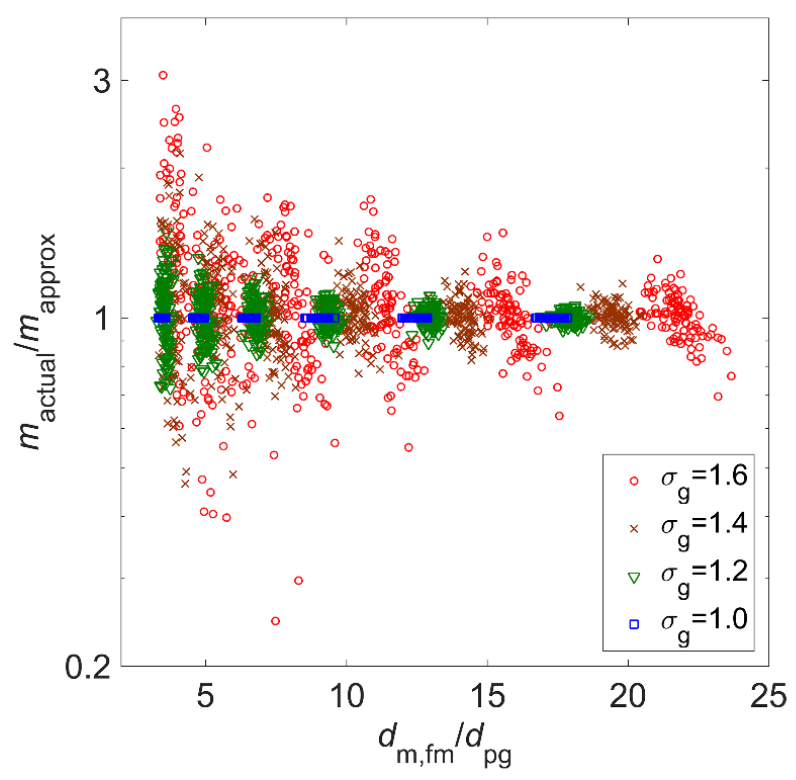

Figure S5: The ratio of actual and approximate masses of particles of different primary particle polydispersity for different normalized free molecular mobility diameters. 


\section{Validation of Stokesian Dynamics algorithm for doublets and straight chains of monodisperse primary particles}

A doublet of monodisperse primary particles was generated and subjected to uniform flow in four different directions (monomers aligned in $\mathrm{Z}$ axis). Results obtained from SD are compared to those obtained from Lattice Boltzman Method (LBM) and analytical solutions reported by Binder et al. (2006) in Table S1. Drag forces, $F_{\mathrm{d}}$, reported in this Table are normalized with the magnitude of the drag force acting on a single primary particle in the same flow regime $\left(6 \pi \mu d_{\mathrm{p}}\right)$. Results obtained from SD method are less than 5\% different from other methods.

Table S1: Comparison of normalized drag forces acting on doublets in the continuum regime measured from the SD simulations with analytical solutions and LBM.

\begin{tabular}{|c|c|c|c|c|c|}
\hline Flow & Normalized $F_{\mathrm{d}}$ & \multicolumn{2}{|c|}{ Binder et al. (2006) } & \multicolumn{2}{c|}{ Relative difference (\%) } \\
\hline $\mathrm{xyz}$ & SD & Analytical & LBM & SD to Analytical & SD to LBM \\
\hline 001 & 1.23 & 1.29 & 1.27 & -4.9 & -3.3 \\
\hline 101 & 1.33 & 1.36 & 1.36 & -2.3 & -2.3 \\
\hline 100 & 1.43 & 1.43 & 1.4 & 0.0 & 2.1 \\
\hline 111 & 1.37 & 1.36 & 1.35 & 0.7 & 1.5 \\
\hline
\end{tabular}

Straight chains of monodisperse primary particles $\left(N_{\mathrm{p}}=1\right.$ to 1000$)$ were also generated. Each chain was subjected to uniform flow fields in 50 random directions and SD simulation was performed. Mobility diameters of the chains in the continuum regime obtained from SD simulation are illustrated in Figure S6. Our results are in great agreement with those reported by Chan \& Dahneke (1981), Filippov (2000), and Horvath (1974), confirming that there was no computational errors.

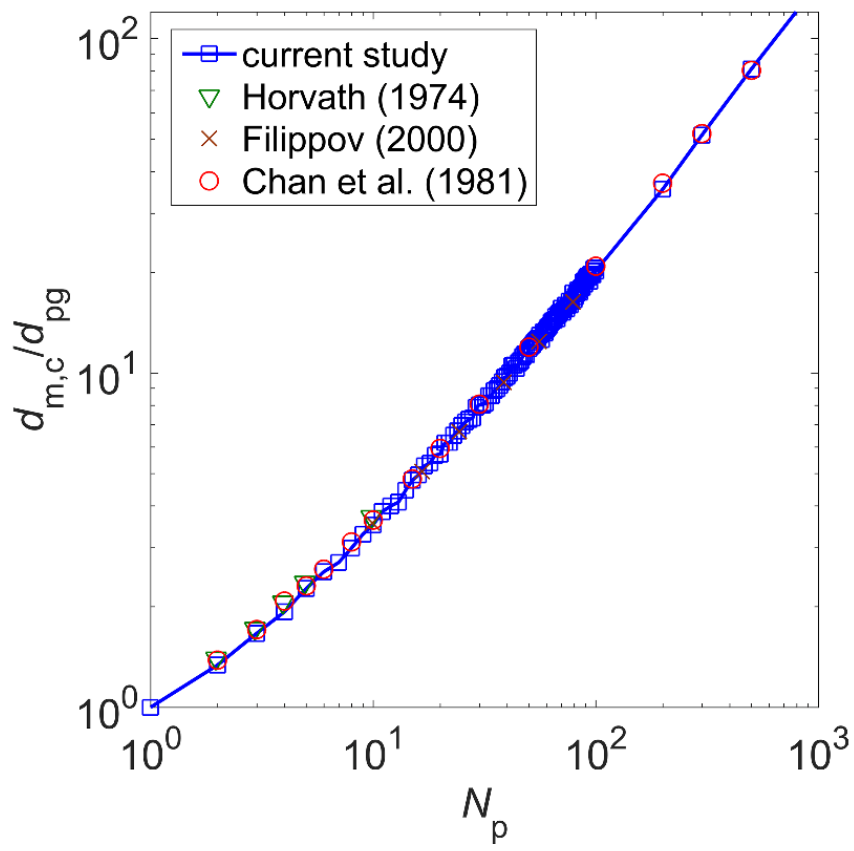

Figure S6: Normalized $d_{\mathrm{m}, \mathrm{c}}$ vs. $N_{\mathrm{p}}$ for straight chains. 


\section{Effect of primary particle polydispersity on continuum mobility diameter}

Variation of the normalized continuum mobility diameter of fractal agglomerates, $d_{\mathrm{m}, \mathrm{c}} / d_{\mathrm{pg}}$, with $\sigma_{\mathrm{g}}$ is illustrated in Figure S7. Similar to the free molecular regime, continuum mobility diameter increases with primary particle polydispersity. This increase is approximately $5 \%$ at $\sigma_{\mathrm{g}}=1.2$ and $23 \%$ at $\sigma_{\mathrm{g}}=1.6$.

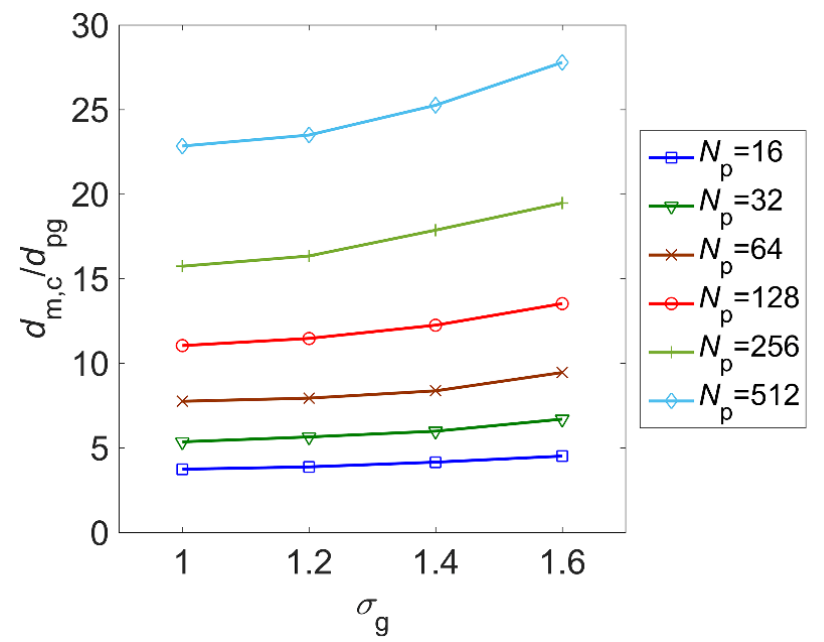

Figure S7: Variation of normalized $d_{\mathrm{m}, \mathrm{c}}$ with $\sigma_{\mathrm{g}}$ in agglomerates of different sizes.

\section{Effect of primary particle polydispersity on the mobility of agglomerates fully aligned in the continuum regime}

Aggregates migrating in an electric field, e.g. in differential mobility analyzer, orient in a way that their smallest principle axis of inertia parallels the migration direction. The influence of the particle alignment is also simulated by rotating the grand resistance matric to a reference system defined by the directions of the principle axis of inertia. Directions of the principle axis of inertia are equal to the principle eigenvectors of the inertia tensor defined as follows:

$$
\overline{\bar{I}}_{x, y, z}=\left[\begin{array}{ccc}
\sum_{i=1}^{N_{\mathrm{p}}}\left(\left(y_{\mathrm{i}}-y_{\mathrm{cm}}\right)^{2}+\left(z_{\mathrm{i}}-z_{\mathrm{cm}}\right)^{2}\right) & -\sum_{i=1}^{N_{\mathrm{p}}}\left(\left(x_{\mathrm{i}}-x_{\mathrm{cm}}\right)\left(y_{\mathrm{i}}-y_{\mathrm{cm}}\right)\right) & -\sum_{i=1}^{N_{\mathrm{p}}}\left(\left(x_{\mathrm{i}}-x_{\mathrm{cm}}\right)\left(z_{\mathrm{i}}-z_{\mathrm{cm}}\right)\right) \\
-\sum_{i=1}^{N_{\mathrm{p}}}\left(\left(y_{\mathrm{i}}-y_{\mathrm{cm}}\right)\left(x_{\mathrm{i}}-y_{\mathrm{cm}}\right)\right) & \sum_{i=1}^{N_{\mathrm{p}}}\left(\left(x_{\mathrm{i}}-x_{\mathrm{cm}}\right)^{2}+\left(z_{\mathrm{i}}-z_{\mathrm{cm}}\right)^{2}\right) & -\sum_{i=1}^{N_{\mathrm{p}}}\left(\left(y_{\mathrm{i}}-y_{\mathrm{cm}}\right)\left(z_{\mathrm{i}}-z_{\mathrm{cm}}\right)\right) \\
-\sum_{i=1}^{N_{\mathrm{p}}}\left(\left(z_{\mathrm{i}}-z_{\mathrm{cm}}\right)\left(x_{\mathrm{i}}-x_{\mathrm{cm}}\right)\right) & -\sum_{i=1}^{N_{\mathrm{p}}}\left(\left(z_{\mathrm{i}}-y_{\mathrm{cm}}\right)\left(y_{\mathrm{i}}-y_{\mathrm{cm}}\right)\right) & \sum_{i=1}^{N_{\mathrm{p}}}\left(\left(x_{\mathrm{i}}-x_{\mathrm{cm}}\right)^{2}+\left(y_{\mathrm{i}}-y_{\mathrm{cm}}\right)^{2}\right)
\end{array}\right]
$$

where $x_{i}, y_{i}$, and $z_{i}$ are the coordinates of the $i^{\text {th }}$ primary particle; and $x_{\mathrm{cm}}, y_{\mathrm{cm}}$, and $z_{\mathrm{cm}}$ are the coordinates of the center of the mass of the agglomerate.

As shown in Figure S8, continuum mobility diameter of fractal agglomerates fully aligned in an external field $\left(d_{\mathrm{m}, \mathrm{c}, \mathrm{I}}\right)$ is approximately 0.94 of the average $d_{\mathrm{m}, \mathrm{c}}$ and almost independent of $\sigma_{\mathrm{g}}$. 


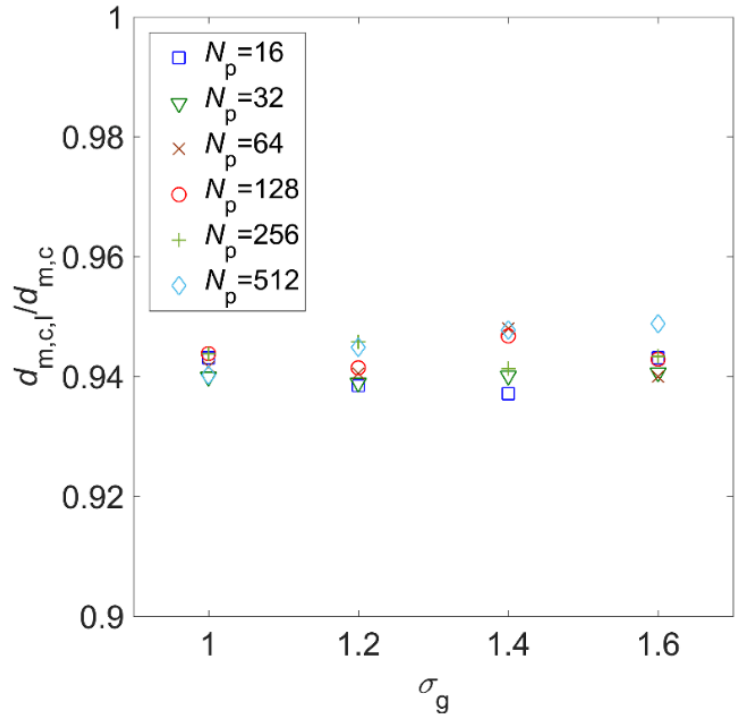

Figure S8: Variation of $d_{\mathrm{m}, \mathrm{c}, \mathrm{I}} / d_{\mathrm{m}, \mathrm{c}}$ with primary particle polydispersity.

\section{References:}

Binder, C., Feichtinger, C., Schmid, H., Thürey, N., Peukert, W., \& Rüde, U. (2006). Simulation of the hydrodynamic drag of aggregated particles. Journal of Colloid and Interface Science, 301(1), 155-67. doi: $10.1016 /$ j.jcis.2006.04.045

Boies, A. M., Stettler, M. E. J., Swanson, J. J., Johnson, T. J., Olfert, J. S., Johnson, M., .. Rogak, S. N. (2015). Particle Emission Characteristics of a Gas Turbine with a Double Annular Combustor. Aerosol Science and Technology, 49(9), 842-855. doi: 10.1080/02786826.2015.1078452

Chan, P., \& Dahneke, B. (1981). Free-molecule drag on straight chains of uniform spheres. Journal of Applied Physics, 52(5), 3106. doi: 10.1063/1.329173

Dankers, S., \& Leipertz, A. (2004). Determination of Primary Particle Size Distributions from TimeResolved Laser-Induced Incandescence Measurements. Applied Optics, 43(18), 3726. doi: 10.1364/AO.43.003726

Dastanpour, R., \& Rogak, S. N. (2014). Observations of a correlation between primary particle and aggregate size for soot particles. Aerosol Science and Technology, 48(10), 1043-1049. doi: $10.1080 / 02786826.2014 .955565$

Dastanpour, R., Rogak, S. N., Graves, B., Olfert, J., Eggersdorfer, M. L., \& Boies, A. M. (2015). Improved sizing of soot primary particles using mass-mobility measurements. Aerosol Science \& Technology, accepted for publication.

Filippov, A. (2000). Drag and Torque on Clusters of N Arbitrary Spheres at Low Reynolds Number. Journal of Colloid and Interface Science, 229(1), 184-195. doi: 10.1006/jcis.2000.6981

Graves, B., Olfert, J., Patychuk, B., Dastanpour, R., \& Rogak, S. (2015). Characterization of Particulate Matter Morphology and Volatility from a Compression-Ignition Natural-Gas Direct-Injection Engine. Aerosol Science and Technology, 49(8), 589-598. doi: 10.1080/02786826.2015.1050482 
Horvath, H. (1974). The sedimentation behavior of non-spherical particles. Staub Reinhalt. Reinhalt. Luft, 34, 197-202.

Johnson, T. J., Olfert, J. S., Symonds, J. P. R., Johnson, M., Rindlisbacher, T., Swanson, J. J., ... Wang, J. (2015). Effective Density and Mass-Mobility Exponent of Aircraft Turbine Particulate Matter. Journal of Propulsion and Power, 31(2), 573-582. doi: 10.2514/1.B35367

Liu, F., Stagg, B. J., Snelling, D. R., \& Smallwood, G. J. (2006). Effects of primary soot particle size distribution on the temperature of soot particles heated by a nanosecond pulsed laser in an atmospheric laminar diffusion flame. International Journal of Heat and Mass Transfer, 49(3-4), 777-788. doi: 10.1016/j.ijheatmasstransfer.2005.07.041

Wu, Y., Cheng, T., Zheng, L., \& Chen, H. (2015). A Study of Optical Properties of Soot Aggregates Composed of Poly-Disperse Monomers Using the Superposition T-Matrix Method. Aerosol Science and Technology, 49(10), 941-949. doi: 10.1080/02786826.2015.1083938 